\title{
THE ISSUE OF THE FREE SURFACE OF ADSORBENT IN THE DESCRIPTION OF A MONOLAYER MOBILE GAS ADSORPTION ON SOLIDS
}

\author{
Jerzy K. Garbacz'1), Jerzy Ciechalski²), Mariusz Kozakiewicz ${ }^{3)}$ \\ ${ }^{1}$ Cuiavian University in Włocławek Faculty of Social and Technical Sciences, Poland \\ 2 University of Technology and Life Sciences in Bydgoszcz, Department of Environment Engineering, Poland \\ ${ }^{3}$ Nicolaus Copernicus University in Torun L. Rydygier Collegium Medicum in Bydgoszcz, Department of Food Chemistry, Poland
}

\section{ABSTRACT}

This paper characterises the concept of monolayer mobile gas adsorption on a homogeneous surface of a solid. The theoretical basis of the phenomenological variant of the description of adsorption equilibrium in the system in question are discussed. The essential features of the solutions to date are discussed, and the effect of the free surface of adsorbent on the form of the final adsorption equation is stressed.

An alternative concept of the free surface based on the modified two-dimensional analogue of Reiss, Frisch and Lebowitz equations is also presented. The obtained adsorption equation was tested for critical parameters of two-dimensional condensation of the adsorption layer, and then used to describe the experimental data available in literature. The verification carried out confirmed the correctness and usefulness of the proposed concept. Keywords: adsorption, monolayer, mobility, two-dimensional condensation.

\section{ARTICLE INFO}

PolHypRes 2019 Vol. 69 Issue 4 pp. $33-44$

ISSN: 1734-7009 elSSN: 2084-0535

DOI: $10.2478 /$ phr-2019-0018

Pages: 12, figures: 3 , tables: 1

page www of the periodical: www.phr.net.pl

Original article

Submission date: 07.09.2019 r

Acceptance for print: 19.10.2019 r.

Publisher

Polish Hyperbaric Medicine and Technology Society 


\section{INTRODUCTION}

The concept of mobile monolayer gas adsorption on a homogeneous solid surface is a model alternative to a group of solutions whose common feature is the assumption of the location of adsorbate molecules on the binding surfaces of adsorbent (i.e. Langmuir [1], FowlerGuggenheim [2] and Berezin-Kisielev [3] models). A strong premise for the credibility of this concept was the work of Hill [4], who drew attention to the analogy between the transition of a layer located with the mobile layer and the inhibition of rotation in particles such as ethane. This author, adapting the approach of Pitzer and Gwinn [5], found that the transition in question starts at $T \approx \Delta \varepsilon / 10 \mathrm{R}$, and covers a wide temperature range up to $T \approx \Delta \varepsilon / R$, where $\Delta \varepsilon$ is the potential energy barrier separating adjacent binding sites, while $\mathrm{R}$ is the gas constant.

Since $\Delta \varepsilon$ does not normally exceed $2 \mathrm{~kJ} / \mathrm{mol}$, adsorption should be so rare that even at liquid air temperature a significant mobility of the adsorbate molecules would be expected [6].

In the theoretical description of a mobile adsorption monolayer, the concept of the so-called twodimensional gas is generally accepted, allowing for easy formulation and adaptation of two-dimensional analogues of known gas state equations. The phenomenological variant of this description is based on Gibbs' adsorption equation which takes the following form:

$$
\ln p=-\frac{1}{k T} \int \omega d \sigma+C ; T=\text { const, }
$$

where $\mathrm{k}$ and $\mathrm{C}$ are the Bolzmann and integration constants respectively, while $\mathrm{p}$ and $\mathrm{T}$ are, in the order given, the adsorptive pressure and temperature. Furthermore, $\sigma$ expresses the surface tension of the adsorption layer, which the concept of a two-dimensional gas associates with the two-dimensional pressure, $\pi$, in the relation:

$$
\pi=\sigma_{0}-\sigma
$$

where $\sigma_{0}$ is the value $\sigma$ for pure adsorbent. In the popular, and often applied, model of rigid disks, the adsorbent molecule is treated as an incompressible flat blocking object, in the state of maximum density, with a surface $\omega_{0}$. The obvious double inequality: $\omega_{0}<\omega<\infty$ allows, in this case, to express the concentration of the adsorption layer by means of a dimensionless degree of filling, $\Theta$, according to the definition: $\Theta=\omega_{0} / \omega$, whereby, for monolayer adsorption, $0<\Theta<1$. Therefore, equation (1) may be presented as:

$$
\ln p=\frac{\omega_{0}}{k T} \int \frac{1}{\Theta} \frac{\partial \pi}{\partial \Theta} d \Theta+C^{\prime} ; T=\text { const, }
$$

where $C^{\prime}$ is, similarly to $C$ in equation (1), an integration constant (the need to include these constants is, in both cases, due to the indefinite nature of the integral).

According to formula (3), formulation of the adsorption equation requires knowledge of the function $\pi$ $=\pi(\mathrm{T}, \Theta)$. Among published solutions to this issue, special attention should be paid to the chronologically early equations of Volmer [7] and Hill-de Boer [8,9]. The former is based on a simple model of slightly imperfect gas and has the form:

$$
\mathrm{p}=\frac{\Theta}{\mathrm{K}_{\mathrm{H}}(1-\Theta)} \exp \left(\frac{\Theta}{1-\Theta}\right)
$$

whereas the second, using the two-dimensional analogue of the Van der Waalas equation, is expressed by the formula:

$$
\mathrm{p}=\frac{\Theta}{\mathrm{K}_{\mathrm{H}}(1-\Theta)} \exp \left(\frac{\Theta}{1-\Theta}-\frac{2 \propto}{\mathrm{kT} \omega_{0}} \Theta\right)
$$

Above, the isothermal constant $\mathrm{K}_{\mathrm{H}}$ (Henry's constant) characterises the adsorbate-adsorbent interactions while parameter $2 \alpha / \omega_{0}$ is a measure of adsorbate-adsorbate attraction. As can be seen, the Volmer equation is a case of equation (5) for $2 \alpha / \omega_{0}=0$, which means that there are no attraction interactions in the adsorption layer. On the other hand, both equations take into account mutual repulsion between adsorbed molecules as a result of their finite internal volume, the measure of this effect being the quotient $\Theta /(1-\Theta)$ in the exponent of each of these equations.

From the point of view of the purpose of this work, it is also important that in both discussed cases $\omega 0$ equals the second virial coefficient of rigid discs liquid, $b_{2}^{0}$, i.e. the doubled own surface of a single disc [4]. Thus, in turn the conclusion is drawn, that the adsorption monolayer should in the state of maximum density block only a half of the total surface of the adsorbent. This conclusion raises serious objections of a geometrical nature. It is known that circles of equal diameter occupy 90.690 percent of the plane in a hexagonal arrangement $\left(\omega_{0}=b_{2}^{0} / 1.8138\right)$ and that even in a less favourable, regular configuration, this value amounts to 78.540 percent $\left(\omega_{0}=\right.$ $\left.\mathrm{b}_{2}^{0} / 1.5708\right)$.

These figures reveal the very approximate nature of the description of adsorbate-adsorbate repulsion by the Volmer and Hill-de Boer models, and thus justify attempts at making it more accurate. An effective proposal for this correction was presented by van Dongen (10). By applying virial development of the rigid discs' fluid state equation (without attraction potential), he obtained for $\omega_{0}$ the value of $b_{2}^{0} / 1,8125$, which is different from the strict geometric value by less than 0.1 per cent. Though undoubtedly impressive, the accuracy of this solution is nevertheless connected with such complexity of the adsorption equation that it virtually excludes its attractiveness for use in describing experimental data. This equation, in a more accessible, logarithmic form, takes the following form:

$$
\begin{aligned}
& \ln \left(\frac{\mathrm{p}}{\mathrm{K}_{\mathrm{H}}}\right)=\ln \Theta-4,1319 \ln (1-\Theta)-\mathrm{k}_{\mathrm{m}} \Theta+ \\
& \frac{1-\mathrm{f}(\Theta)}{\mathrm{f}(\Theta)}+1,6374 \ln \left(1-1,3562 \Theta+0,4974 \Theta^{2}\right)+ \\
& 0,1182 \ln \left(1+0,5847 \Theta+0,1307 \Theta^{2}\right)+0,8103 \ln (1- \\
& \left.0,0409 \Theta+0,0369 \Theta^{2}\right)+0,1987 \operatorname{arctg} \frac{0,1939 \Theta}{1-0,6781 \Theta}- \\
& 0,1395 \operatorname{arctg} \frac{0,1911 \Theta}{1-0,0205 \Theta},
\end{aligned}
$$

where $\mathrm{km}_{\mathrm{m}}=1,8125\left(2 \alpha / \mathrm{kTb}_{2}^{0}\right)$, while

$$
\begin{aligned}
& f(\Theta)=1-1,8125 \Theta+0,7162 \Theta^{2}+0,1882 \Theta^{3}-3,758 \\
& 10^{-2} \Theta^{4}-5,274 \cdot 10^{-2} \Theta^{5}+8,682 \cdot 10^{-4} \Theta^{6}-2,401 . \\
& 10^{-2} \Theta^{7}
\end{aligned}
$$


Both the high accuracy of $\omega 0$ and the high complexity of equation (6) are a consequence of the inclusion of as many as eight virial coefficients of the rigid disc fluid in the derivation (the first four can be determined analytically, while the last one is at the limit of modern computing technique).

However, an attempt to limit the extension to a smaller number of expressions gives a significantly worse result. For example, for the first three coefficients, $\omega_{0}$ values equal to $b_{2}^{0} / 1,4730$ were obtained [11]. This would be satisfactory for a regular configuration, but not for a tight hexagonal arrangement of rigid discs. In this situation, it seems reasonable to look for a description that would represent a reasonable compromise between the accuracy of $\omega_{0}$ and the application value of the final adsorption equation. The proposal presented later in this text is the main objective of this paper.

\section{Alternative APPROACH TO THE FREE} SURFACE OF ADSORBENT

The equation of the state of the adsorption layer treated as a two-dimensional gas can be expressed as follows:

$$
\pi_{\mathrm{ef}} \mathrm{A}_{\mathrm{f}}=\mathrm{NkT} \text {, }
$$

where $\pi_{\text {ef }}$ is the effective two-dimensional pressure, i.e. the pressure that would be exerted by the same number, $\mathrm{N}$, of molecules of a two-dimensional perfect gas on the same free surface, $A_{f}$.

The starting point of the van Dongen model [10] was the assumption according to which

$$
A_{f}=A(1-\rho b) \text {, }
$$

where $A$ is the total surface area of the adsorbent, $\rho(=N / A)$ is the density of the adsorption layer, whereas

$$
b=b_{1}+b_{2} \rho+b_{3} \rho^{2}+\cdots
$$

(note that the above extension is a generalisation of the van der Waals model in which $b$ does not depend on gas density).

The substitution of the last two relationships to the equation (8) gives:

$$
\frac{\pi_{\mathrm{ef}}}{\rho \mathrm{kT}}=\frac{1}{1-\rho\left(\mathrm{b}_{1}+\mathrm{b}_{2} \rho+\mathrm{b}_{3} \rho^{2}+\cdots\right)}
$$

In the case of none attracting rigid discs, $\pi_{\mathrm{ef}}=\pi$, the development of the right-hand side of equation (11) in a power series with respect to density, $\rho$, allows the determination of particular bi $(i=1,2,3, \ldots)$ through comparison with the coefficients of the virial development of the state equation. Corresponding transformations result in the adsorption equation (8).

In the opinion of the authors of this work, the need to take into account as many as eight virial coefficients in order to obtain an almost ideal value of $\omega_{0}$ has its source in the unfortunate choice of formula (10) as the basis of the concept. We will show that by choosing a more suitable expression for the free surface of the adsorbent, it is possible to obtain, at much lower cost, only a slightly worse result. For this purpose, let us adopt the two-dimensional analogue of the Reiss, Frich and
Lebowitz's equation [12], according to which

$$
A_{f}=A(1-\rho b)^{2},
$$

where $b=\frac{b_{2}^{0}}{2}$.

By modifying this equation in the spirit of the van Donger concept we obtain:

$$
\frac{\pi}{\rho \mathrm{kT}}=\frac{1}{\left[1-\rho\left(\mathrm{b}_{1}+\mathrm{b}_{2} \rho+\mathrm{b}_{3} \rho^{2}+\cdots\right]^{2}\right.}
$$

In turn, the limitation of the development of the right-hand side of equation (13) in a power series with respect to $\rho$ to no more than the first three expresses gives:

$$
\frac{\pi}{\rho \mathrm{kT}}=1+2 \mathrm{~b}_{1} \rho+\left(2 \mathrm{~b}_{2}+3 \mathrm{~b}_{1}^{2}\right) \rho^{2}
$$

Defining the second and third virial coefficient of the fluid of rigid discs $a s, b_{2}^{0}$ and $b_{3}^{0}$ respectively, we obtain:

$$
\begin{aligned}
& \mathrm{b}_{1}=\frac{\mathrm{b}_{2}^{0}}{2} \\
& \text { and } \\
& \mathrm{b}_{2}=\frac{\mathrm{b}_{3}^{0}-0,75\left(\mathrm{~b}_{2}^{0}\right)^{2}}{2}
\end{aligned}
$$

Taking into account the value of the third virial factor $\quad\left(b_{3}^{0}=0,7820 \quad\left(b_{2}^{0}\right)^{2} \quad(11)\right)$ allows to present a simplified form of equation (13) as follows:

$$
\frac{\pi}{\rho \mathrm{kT}}=\frac{1}{\left[1-\frac{\mathrm{b}_{2}^{0}}{2} \rho-0,0160\left(\mathrm{~b}_{2}^{0}\right)^{2} \rho^{2}\right]^{2}}
$$

Hence, after the transformations

$A_{f}=0,003240 A\left[\left(1-\frac{N b_{2}^{o}}{1,8862 A}\right)\left(17,567+\frac{N b_{2}^{o}}{1,8862 A}\right.\right.$

In a tight arrangement of rigid discs, $\Theta=1$ and $A_{f}$ $=0$. Equation (18) meets these conditions for $\omega_{0}=\mathrm{b}_{2}^{0} / 1,8862$ oraz $\Theta=\mathrm{Nb}_{2}^{0} /(1,8862 \mathrm{~A})$. Bearing in mind that $b_{2}{ }^{0}$ means twice the own surface area of the rigid disc, we see that the proposed description provides for blocking by the adsorption layer, in its maximum concentration of 94.31 per cent of the adsorbent surface area. This result deviates from the strict geometric value by less than 4 percent, and although it is slightly less than the result of the van Dongen method in terms of accuracy, it was achieved with incomparable ease.

This will also produce, as we will demonstrate later in the text, a much less complex final adsorption equation. Meanwhile, let us note that the above findings allow us to write down equation (17) as follows:

$$
\pi=\frac{k T}{b_{2}^{o}} \frac{582,10 \Theta}{[(1-\Theta)(17,567+\Theta)]^{2}}
$$

The full form of the adsorption layer state equation still needs to determine the relation between the quantities $\pi$ and $\pi_{\text {ef. }}$. For this purpose, let us assume that the attracting adsorbate-adsorbate interactions are characterised by potential of the van der Waals type, therefore: 
where $\alpha$ is the same parameter as in equation (5) and $\omega_{0}$, as already established, equals $b_{2}^{0} / 1,8862$.

Returning to Gibbs' equation, (3), using dependencies (20) and (21), and selecting an integration constant, where the low density limit of the solution is Henry's equation [4], gives the following adsorption equation:

$$
\begin{aligned}
& \mathrm{p}= \\
& \frac{\Theta}{\mathrm{K}_{\mathrm{H}}(1-\Theta)}\left(\frac{1-\Theta}{1+0,05692 \Theta}\right)^{8,390 \cdot 10^{-3}} \exp \left\{1,886 \Theta\left[\frac{1,474-\Theta}{(1-\Theta)^{2}}-3,658 .\right.\right. \\
& \left.\left.10^{-5} \frac{22,08+\Theta}{(1+0,05692 \Theta)^{2}}-\frac{2 \propto}{\mathrm{kTb}_{2}^{0}}\right]\right\}
\end{aligned}
$$

An important test of adequacy of the adsorption model due to adsorbate-adsorbate interactions is to verify its effectiveness in predicting two-dimensional condensation of the adsorption layer. The results of this verification are (if they exist at all) the coordinates of the saddle point on the so-called critical isotherm, i.e. the curve $p(\Theta)$ constituting the boundary between the noncondensable gas (supercritical area) and the two-phase gas-liquid system (subcritical area), with all phases being, obviously, two-dimensional.

At this particular inflection point, both the first and the second derivative of the adsorbent pressure will be zeroed in relation to the degree of filling of the adsorbent surface. The solution of an appropriate system of equations gives the critical values of the degree of filling, $\Theta_{c}$ and the adsorbate-adsorbate attraction parameter, $\left(2 \alpha / \mathrm{kTb}_{2}^{0}\right)_{\mathrm{c}}$. It should be stressed at this point that not every adsorption equation passes the discussed test; physically reasonable values of critical parameters are obviously not given by the Langmuir and Volmer equations, but also by the otherwise valuable Berezin and Kisielev equations (3). Acceptable solutions, on the other hand, apply to the equations (5) and (6) quoted in this work. The calculated values for them are, respectively:

$\checkmark$ for equation (5): $\Theta_{\mathrm{c}}=1 / 3, \quad\left(2 \alpha / \mathrm{kTb}_{2}^{0}\right)_{\mathrm{c}}=27 / 4$ (these are exact values, thus we provide them in the form of rational numbers),

$\checkmark$ for equation (6): $\Theta_{\mathrm{c}}=0.2333,\left(2 \alpha / \mathrm{kTb}_{2}^{0}\right)_{\mathrm{c}}=5.917$. The Hill-de Boer equation (5) is, as already mentioned, a formula based on a rough approximation of the value of $\omega_{0}\left(\omega_{0}=b_{2}^{0}\right)$. For this reason it seems right to choose critical parameters of equation (6) as a criterion for evaluating the solution (21) in the aspect of describing a two-dimensional phase transition in the adsorption layer. According to the cautious opinion of the authors, this evaluation is unexpectedly good, as the standard procedure here yields values: $\Theta=0.2212$ and $\left(2 \alpha / \mathrm{kTb}_{2}^{0}\right)_{\mathrm{c}}=5,947$, i.e. different (as rounded) from the reference ones by 5 and 0.5 per cent respectively. Taking into account the inevitably approximate nature of each model, these differences can be treated without risk as insignificant.

\section{DESCRIPTION OF EXPERIMENTAL DATA}

The evaluation of the presented model also includes the result of confronting equation (21) with experimental adsorption equations.

Below are the results of the application of this solution to describe the literature data for the following three adsorbate/adsorbent systems:

A. sulphur hexafluoride/graphitised carbon black [13],; $\mathrm{T}=193,5 \mathrm{~K},[\mathrm{p}]=$ Torr, [a] $=\mu \mathrm{mol} / \mathrm{m}^{2}$ (here and in other cases $\mathrm{a}$ is the absolute value of adsorption),

A. trichlorofluoroethane/boron nitride [14]; $\mathrm{T}=240,9 \mathrm{~K},[\mathrm{p}]=\mathrm{mmHg}[\mathrm{a}]=\mu \mathrm{mol} / \mathrm{g}$,

B. benzene/graphitised carbon black [14]; $\mathrm{T}=308,2$ $\mathrm{K},[\mathrm{p}]=\mathrm{mmHg},[\mathrm{a}]=\mathrm{cm}^{3} / \mathrm{g}$.

In the case of arrangement $A$, tabulated pressure and adsorption values were used. In the other two cases, data in the form of graphs were initially digitalised. The best fit method was used, while preserving the units used by the authors of the experimental data, to determine the optimal parameter values: $\mathrm{K}_{\mathrm{H}},\left(2 \alpha / \mathrm{kTb}_{2}^{0}\right)$ and monolayer adsorption capacity, $\mathrm{am}_{\mathrm{m}}$. The latter, assumedly independent of temperature, occurs in an alternative definition of the degree of surface filling $\Theta=\mathrm{a} / \mathrm{am}$, determining the adsorption limit for $\mathrm{p} \rightarrow \infty$.. The results obtained are presented in Table 1. The last column of this table contains values of the curvilinear correlation coefficient, $r$, adopted as a measure of the goodness of fit.

\begin{tabular}{|c|c|c|c|c|c|}
\hline Adsorption model & $\begin{array}{ll}\begin{array}{l}\text { Literature data } \\
\text { source }\end{array} & \\
\end{array}$ & KH (unit) & $2 \alpha / \mathrm{kTb} 2^{\wedge} 0$ & am (unit) & $r$ \\
\hline $\mathrm{A}$ & [13] & $\overline{2} 1.198^{*}$ (Torr $^{-1}$ ) & 5.391 & $11.10\left(\mu \mathrm{mol} / \mathrm{m}^{2}\right)$ & 0.9972 \\
\hline B & {$[14]$} & $\overline{2} 3.950\left(\mathrm{mmHg}^{-1}\right)$ & 6.190 & $4.046(\mu \mathrm{mol} / \mathrm{g})$ & 0.9988 \\
\hline $\mathrm{C}$ & [14] & $\overline{1} 1.603\left(\mathrm{mmHg}^{-1}\right)$ & 1.764 & $2.518\left(\mathrm{~cm}^{3} / \mathrm{g}\right)$ & 0.9986 \\
\hline
\end{tabular}

${ }^{*}$ entry $\overline{2} 1.198$ means the value $1.198 \cdot 10^{-2}$; as in all other cases.

The quality of description of experimental data using equation (21) is illustrated in Figures 1-3. 


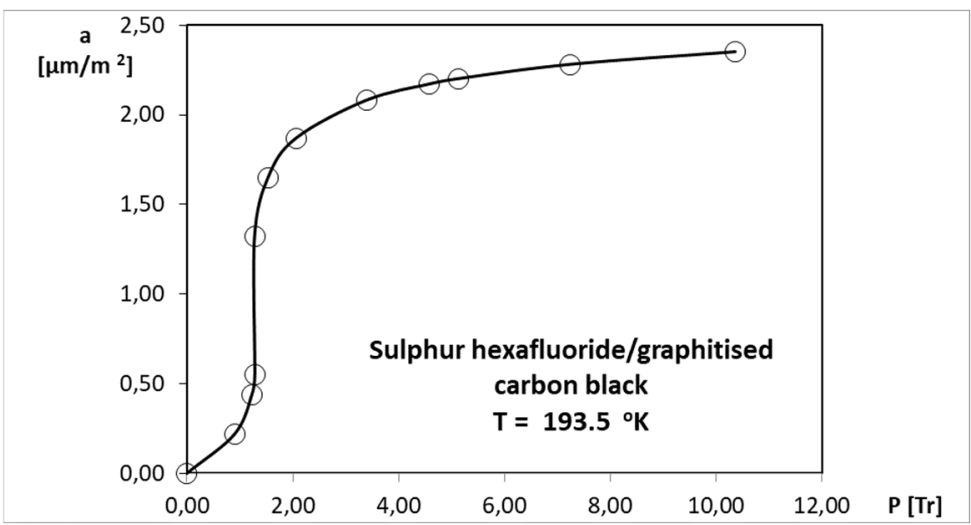

Fig. 1 Adsorption isotherm in model A (SF6/graphitised carbon black); experimental data circles (see Table 1), continuous line - equation (21).

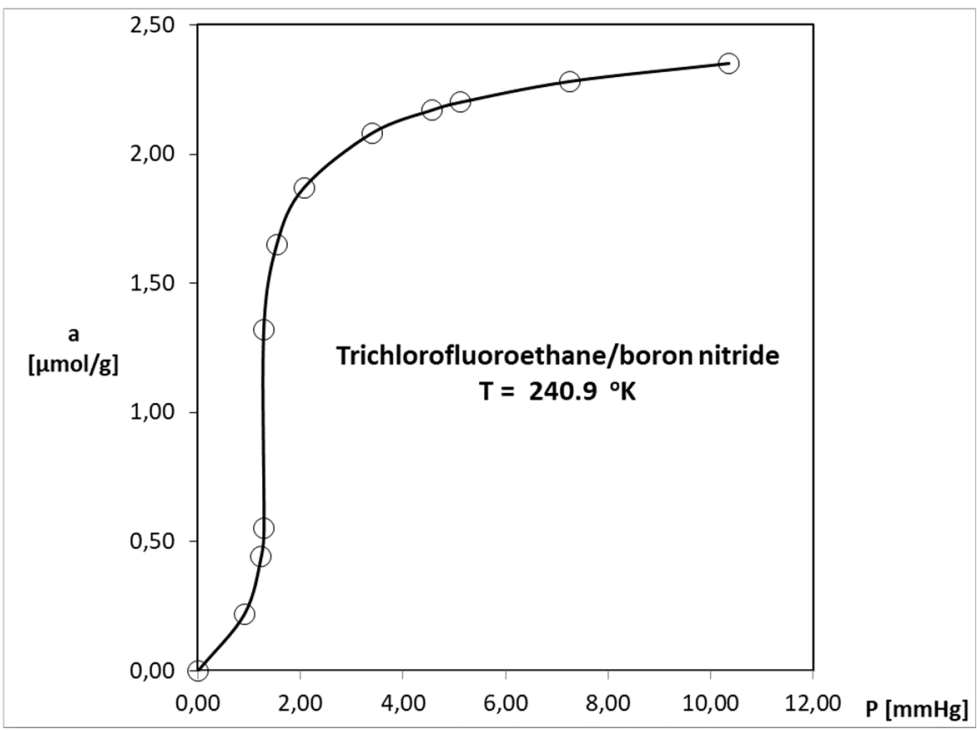

Fig. 2 The same for model $\mathrm{B}\left(\mathrm{CFCl}_{3} / \mathrm{BN}\right)$.

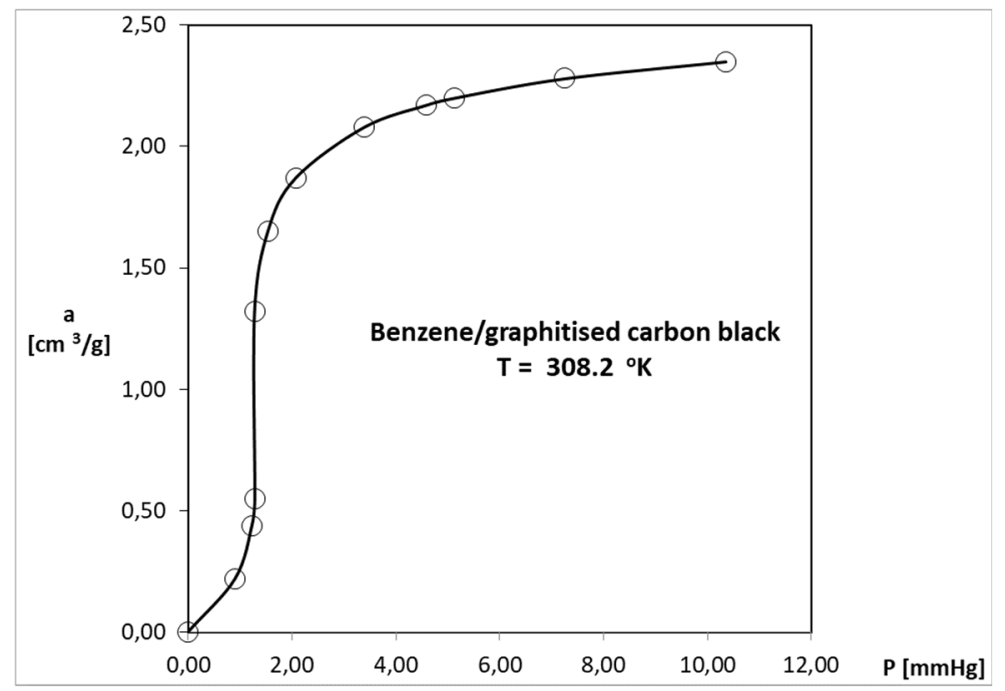

Fig. 3 The same for model $\mathrm{C}\left(\mathrm{C}_{6} \mathrm{H}_{6} /\right.$ graphitised carbon black). 
As can be seen, the optimisation of parameters carried out gave a high, and practically identical, accuracy in reproducing experimental data using equation (21) in all three described models. This is evidenced by the close to unity values of the coefficient $r$, which is confirmed by respective illustrations. It should be emphasised that the tested adsorption equation, depending on the value of parameter $\left(2 \alpha / \mathrm{kTb}_{2}^{0}\right)$, equally successfully describes sigmoidal isotherms (here, both subcritical in model $A$ and supercritical in B) and hyperbolic isotherms (as in C), which is an additional reason for its positive assessment.

\section{ConClusions}

- An expression describing the free surface of adsorbent is one of the essential factors determining the form of the mobile gas adsorption equation for solids.

- The popular Volmer and Hill-de Boer models, which identify the second virial coefficient of the fluid of the rigid discs with the surface effectively blocked by the adsorbate molecule, give, compared with the geometric value, an approximately forty percent underestimation of the surface blocked by a fully formed adsorption monolayer.
- The van Dongen method leads to an almost ideal compliance of $\omega 0$ with the geometric criterion, thus determining the reference values of the critical parameters of the two-dimensional adsorption layer condensation. However, the complexity of the adsorption equation corresponding to this method is so high that it effectively limits its attractiveness for use in describing experimental data.

- The model presented in this paper, using the development limited to only the first three coefficients of fluid of rigid discs, yields a much simpler adsorption equation, and its prediction of critical parameter values is insignificantly different from reference values. The usefulness of the proposed solution is also confirmed by its high efficiency in the description of experimental adsorption isotherms.

The positive result of the plausibility tests of the proposed concept presented in this article allows, in the opinion of the authors, to recognise its theoretical correctness and usefulness for the description of isothermal adsorption data, as well as to successfully predict the next stages of its verification; this time in terms of temperature characteristics of the discussed phenomenon.

\section{REFERENCES}

1. Langmuir I. The Adsorption of Gases on Plane Surfaces of Glass, Mica and Platinum. J Am Chem Soc. 1918;40:1361-403;

2. Fowler RH, Guggenheim EA. Statistical thermodynamics; a version of statistical mechanics for students of physics and chemistry. New York, Cambridge, Eng.,: The Macmillan Company; The University Press; 1939. x, 693 p.;

3. Berezin GI, Kiselev AV. Adsorbate-Adsorbate Association on a Homogenous Surface of a Nonspecific Adsorbent. 1. J Colloid Interf Sci. 1972;38(1):227-\&:

4. Hill TL. Statistical Mechanics of Multimolecular Adsorption .2. Localized and Mobile Adsorption and Absorption. Journal of Chemical Physics. 1946;14(7):441-53;

5. Pitzer KS, Gwinn WD. Energy levels and thermodynamic functions for molecules with internal rotation I rigid frame with attached tops. Journal of Chemical Physics. 1942;10(7):428-40;

6. Young DM, Crowell AD. Physical adsorption of gases. London,: Butterworths; 1962. xi, 426 p;

7. Volmer M. Thermodynamic conclusions derived from the state equation for absorbed substances. Z Phys Chem-Stoch Ve. 1925;115(3/4):25360;

8. Hill TL. Theory of Physical Adsorption. Adv Catal. 1952;4:211-58;

9. Boer JHd. The dynamical character of adsorption. Oxford,: Clarendon Press; 1953. xv, 239 p. ;

10. Boer JHd, Linsen BG. Physical and chemical aspects of adsorbents and catalysts; dedicated to J. $\mathrm{H}$. de Boer on the occasion of his retirement from the Technological University, Delft, The Netherlands. London, New York,: Academic Press; 1970. xxiv, 650 p.;

11. Garbacz JK. Towards More Accurate Specification of Conception - Adsorbate-Adsorbate Association in Cases of Multilayer Adsorption on Homogeneous Surfaces. Pol J Chem. 1978;52(10):1973-83;

12. Reiss H, Frisch HL, Lebowitz JL. Statistical Mechanics of Rigid Spheres. Journal of Chemical Physics. 1959;31(2):369-80;

13. Beebe RA, Kiselev AV, Kovaleva NV, Tyson RFS, Holmes JM. Adsorption and State of Co2, Sf6 and Nh3 on a Graphitized Carbon Surface . 1. Adsorption Isotherms. Zh Fiz Khim+. 1964;38(3):708-18;

14. Ross S, Olivier JP. On physical adsorption. New York,: Interscience Publishers; 1964. 401 p.

prof. dr hab. Jerzy K. Garbacz

Uniwersytet Technologiczno-Przyrodniczy w Bydgoszczy,

Wydział Budownictwa, Architektury i Inżynierii Środowiska,

Katedra Ekoinżynierii i Fizykochemii Środowiska

ul. Sucha 9, 85-789 Bydgoszcz

(52) $3408440 / 3408445$

jerzy.garbacz@utp.edu.pl 